\title{
Aminopirinin Yeni Bir Renk Reaksiyonunun Mekanizmasi Üzerinde Çalışmalar
}

Etude Sur le Méchanisme Réactionnel de la Nouvelle Colorimetrie de l'Aminopyrine

\author{
Feyyaz ONUR*
}

Ö Z E T

Aminopirinin $\mathrm{NH}_{4} \mathrm{SCN}$ tuzu benzaldehitte çözüldüğünde çözeltinin rengi sırasılla mavi->mor-sarı şeklinde değişmekte, sonra renksiz olmaktadır. IR, ESR, NMR ve MS ile yapılan çalışmalar sonucunda bu reaksiyonun mavi renkli bir radikal oluşumu ile başlayan oksidasyon olduğu ve bis-(1-fenil-2-metil-4-hidroksi-5-okso-pirazolinil$3)$-etan bileşiğinin meydana gelmesi ile sona erdiği saptand.

\section{RESUME}

Quand on dissout l'aminopyrine $\mathrm{NH}_{4} \mathrm{SCN}$ dans bénzaldehyde la couleur de la solution devient bleu-violette->jaune et puis incolore. Selon nos études faites par IR, ESR, NMR et MS, nous avons determiné que cette reéaction était une oxydation qui commencait par apparition d'un radical dont la couleur était bleu et qui finissait par la production de bis- (1-phényl-2-méthyl-4-hydroxy-5-oxo-pyrazolinyl-3)-éthane.

Anahtar kelimeler: Piramidón, aminopirin, oksidasyon, benzaldehit, NMR, ESR, IR.

\section{G İ R İ Ş}

Önceki çalışmamızda (1) aminopirinin $\mathrm{NH}_{4} \mathrm{SCN}$ tuzunun benzaldehitte çözüldüğünde çözeltinin sırasıyla mavi-mor->sarı şeklinde

Redaksiyona verildiği tarih: 8.4.1986

* Analitik Kimya Anabilim Dalı, Eczacılık Fakültesi, Ankara Üniversitesi. 
geçici renklendiği ve uzun bir zaman sonra renksiz olduğu, ayrıca beyaz renkli katı bir bileşiğin meydana geldiği gözlenmişti. Sonra bu dizi renklerden ilk oluşan mavi renk ortama (1:1) oranında benzilalkol ilave edilerek bir miktar tayini için gerekli ve yeter sürede $(\sim 10 \mathrm{dk})$ dayanıklı hale getirildikten sonra aminopirinin spektrofotometrik olarak miktar tayini gerçekleştirilmiştir.

Bu çalışmada ise gözlenen renk değişiminin mekanizmasının araştırılması amaçlanmıştır.

Bugüne kadar yapılan çalışmalarda aminopirinin sulu ortamda $\mathrm{FeCl}_{3}, \mathrm{HNO}_{2}, \mathrm{HIO}_{3}, \mathrm{H}_{2} \mathrm{O}_{2}, \mathrm{AgNO}_{3}$ ve $\mathrm{O}_{2}$ ile reaksiyonumuza benzer bir renk değişimi ile reaksiyon verdiği belirtilmektedir (3-10). Aynı çalışmalarda bu reaksiyonun mekanizması üzerinde de araştırmalar yapıldığı ve reaksiyonun radikalik bir oluşum ile başlayan oksidasyon olduğu ileri sürülerek oluşan bileşiklerin formülleri verilmeye çalışılmaktadır $(5,8,9)$.

DENEL KISIM

\section{Materyal ve Yöntem}

Çalışmalarda KAUFMANN (2)'a göre hazırlanan aminopirin $\mathrm{NH}_{4} \mathrm{SCN}$ tuzu, benzaldehit (Analar) ve benzil alkol (Merck) kullanild.

Aminopirin $\mathrm{NH}_{4} \mathrm{SCN}$ hazırlanması (2): $500 \mathrm{mg}$ aminopirin ile $165 \mathrm{mg}$ amonyum sulfosiyanür $60 \mathrm{ml}$ su içinde hafifçe isıtılarak çözülür, sonra buzda kristallendirilir. Bis-(1-fenil-2-metil-4-hidroksi-5okso-pirazolinil-3)-etan hazırlanması (5): 1.8 gr aminopirin, 180 $\mathrm{ml} 0.1 \mathrm{~N} \mathrm{KIO}_{3}$ çözeltisi ve $4.5 \mathrm{ml} \% 20 \mathrm{H}_{2} \mathrm{SO}_{4}$ bir saat boyunca geri çevirici soğutucuya bağlı olarak su banyosunda 1sıtılır. Yaklaşık yarım saatlik bir reaksiyon süresinden sonra kırmızı kahve rengi bir çökelti ayrılmaya başlar. Nuce krozesinden süzüldükten sonra çökelek kurutulur. Daha sonra $20 \mathrm{ml}$ tetrahidro hıran ile geri çevirici altında kısa süre kaynatılır. Madde bir kısmı koyu kırmızı renk alarak çözeltiye geçer. Açık sarı renkli kalıntı 0.36 gr gelir ve bu hazırlanmak istenen bileşiktir. (Erime noktası $280^{\circ} \mathrm{C}$ dir)

Reaksiyonumuzun bir renk değişimi reaksiyonu olması nedeniyle mekanizmanın araştırılması için öncelikle oluşan herbir renkteki maddenin saf halde elde edilerek analizinin yapılması gerekir. Ama yapı- 
lan çalışmalarda çözeltide değişken renklerin oluştuğu anda bu renkli maddelerin tek tek çözücüyü uçurma, distilasyon, başka çözücü ilavesi, ortamın pH mı değiştirme, sıcaklığın düşürülmesi, katı faza adsorbe etmek gibi yöntemler ile katı halde elde edilmesi sağlanamadı. Dolayısıyla bu renk değişimi UV, IR, NMR, ESR gibi enstrümental analiz yöntemleri ile izlendi. Ayrıca reaksiyonun sonunda oluşan artık maddenin analizi yapıldı.

\section{B U L G ULAR}

\section{1) Spektrofotometrik çalışmalar}

Aminopirin $\mathrm{NH}_{4} \mathrm{SCN}$ tuzunun benzaldehit ve benzaldehitbenzilalkol (1:1) karışımındaki çözeltilerinin çözücü referans olarak kullanılarak alınan spektrumlarında (SP8-100 UV - visible spektrofotometresinde) çözeltinin renginin mavi olduğu anda max. absorbsiyonun $590 \mathrm{~nm}$ de olduğu ve zamanla daha düşük dalga boylarına kayarak rengin sarı olduğu anda da $420 \mathrm{~nm}$ ye kadar indiği görüldü. Dalga boyundaki bu kayma çözücü olarak benzaldehit kullanıldığında çok hızlı olarak meydana gelmektedir. Benzaldehit-benzilalkol (1:1) çözücü olarak kullanıldığında ise $590 \mathrm{~nm}$ deki absorbsiyon yaklaşık $10 \mathrm{dk}$. kadar sabit kalmaktadır. $590 \mathrm{~nm}$ deki bu absorbsiyonun $\log$ s si 2.69 olarak hesaplandı. $350 \mathrm{~nm}$ nin altındaki dalga boylarında ise çözücünün referans olarak kullanılmasına rağmen spektrum alınamadi.

\section{2) IR ile yapılan çalışmalar}

Yine çözeltideki renk değişimi sırasında 2 şer dakika aralıklar ile üst üste IR spektrumları alınd1. $0.5 \mathrm{~mm} \mathrm{NaCl}$ pencereli sıvı hücrelerinin kullanıldı̆̆ zaldehit ve benzaldehit-benzilalkol (1:1).

IR spektrumlarına bakıldığında çözücü olarak benzaldehit kullanıldı ̆̆ında $2040 \mathrm{~cm}^{-1}$ de tipik $\mathrm{SCN}$ grubuna ait $(-\mathrm{S}-\mathrm{C} \equiv \mathrm{N})$ pikin yanısıra 620-640 $\mathrm{crm}^{-1}$ de şiddeti zamanla azalan geniş ve yaygın bir pik daha olduğu, bunların dışında ise yorumlabilecek başka piklerin olmadığı gözlendi. Çözücü olarak benzaldehit-benzilalkol (1:1) kullanıldı̆̆ında benzaldehitte gözlenen 620-640 $\mathrm{cm}^{-1}$ deki pikin kaybolduğu, ayrıca $2040 \mathrm{c} \mathrm{m}^{-1}$ deki SCN grubuna ait pikin şiddetinin he- 
men hemen yarıya indiği (konsantrasyonları eşit ve \% 2) ve reaksiyon sırasında da şiddetinin çok yavaş biçimde azalmaya devam ettiği gözlenmektedir. $\mathrm{Bu}$ sonuçlara bakarak reaksiyonda $\mathrm{SCN}$ grubunun önemli rol oynadığı anlaşılmaktadır.

\section{3) ESR ile yapılan analizler}

Daha önceki çalışmalarda aminopirinin sulu ortamda benzeri reaksiyonlarda radikalik bir halin meydana geldiği belirtilmektedir (3-10). Reaksiyonumuzun bu yönden analizi için ESR yönteminden yararlanıld1. Varian E-15 X-Band ESR spektrometresinde aminopirin $\mathrm{NH}_{4} \mathrm{SCN}$ tuzunun benzaldehit-benzilalkol (1:1) karışımı içindeki çözeltisinin renk değişimi sırasında spektrumu alındı (Şekil 1). Aynı maddenin benzaldehitte spektrumu ise alınamadı. Çünkü bu çözücüdeki renk değişimi spektrum almak için gerekli süreden daha kısa bir sürede gerçekleşmekte, dolayısıyla spektrumda herhangi bir pike rastlanmamaktadir.

Elde edilen spektrumda (Şekil 1) 3370 gauss'ta ve $9.53 \mathrm{GHz}$ te tek bir pikin olduğu görülmektedir.

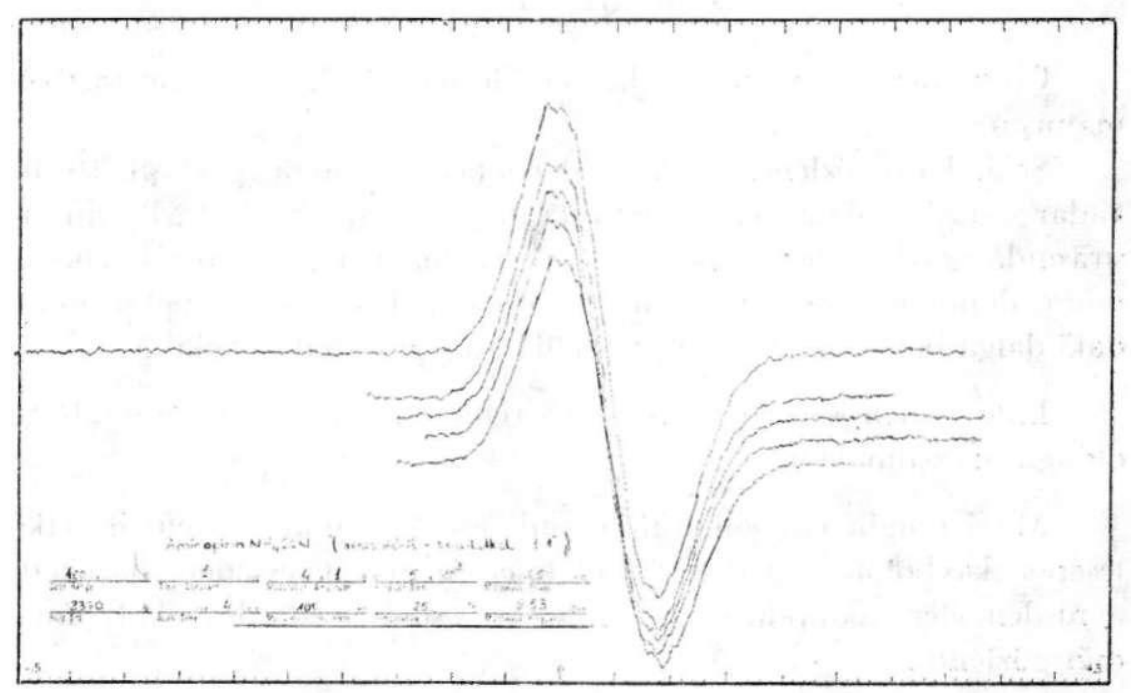

Şekil 1. Aminopirin $\mathrm{NH}_{4} \mathrm{SCN}$ tuzunun benzaldehit -benzilalkol (1:1) karışımındaki çözeltisinin 1 er dakika aralıklar ile alınmış ESR spektrumu. 


$$
h \cdot \nu=g_{E} \cdot \beta_{E} \cdot H
$$

eşitliğinde bu değerler yerine konulursa:

$$
\begin{aligned}
\left(\begin{array}{lll}
6.62 \times 10^{-27} & \left(9.53 \times 10^{9}\right.
\end{array}\right)=g_{\mathrm{E}}\left(9.27 \times 10^{-27}\right) \quad \times 3370 \\
\mathrm{~g}_{\mathrm{E}}=2.0195
\end{aligned}
$$

bulunmaktadır ki bu değer ortamda serbest bir radikalin meydana geldiğini göstermektedir.

Bu radikal şu şekildedir $(8,9)$ : (Formül 1)

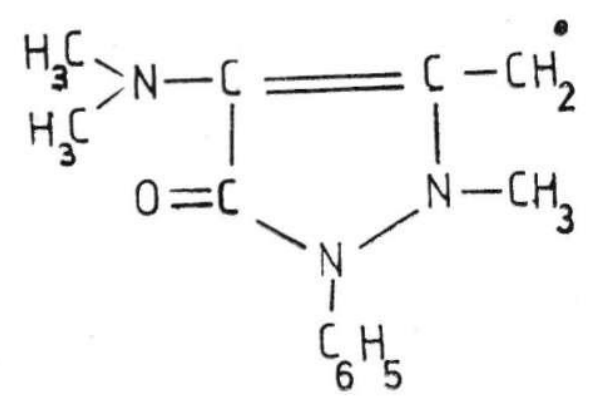

\section{FormüL 1}

Çözücülerin aynı şartlarda kendilerine ait ESR pikine rastlanmamıştır.

Şekil 1 de gözlenen pikin şiddeti önce artmakta, yaklaşık $10 \mathrm{dk}$. kadar sabit kaldıktan sonra zamanla düşmektedir (Şekil 2). Bu düşme sırasında gözle izlendiğinde çözeltinin mavi rengininde kaybolup mora döndüğü görülmektedir. Bu durum UV-visible spektrumundaki dalga boyu kayması ile paralellik göstermektedir (Şekil 3).

Elde edilen sonuçlardan mavi rengin radikalik oluşuma bağlı olduğu anlaşılmaktadır.

Mavi rengin kaybolmasının, radikalin havanın oksijeni ile etkileşerek kaybolması nedeniyle olabileceği düşüncesinden hareketle aynı deneyler vakumda tekrarlandı. Ama sonuçlarda değişiklik olmadığ 1 gözlendi.

$-197^{\circ} \mathrm{C}$ da sivı azot içerisinde alınan ESR spektrumunda da aynı tek pik göslendi ve bu pikin şiddetinde zamanla bir azalmanın 


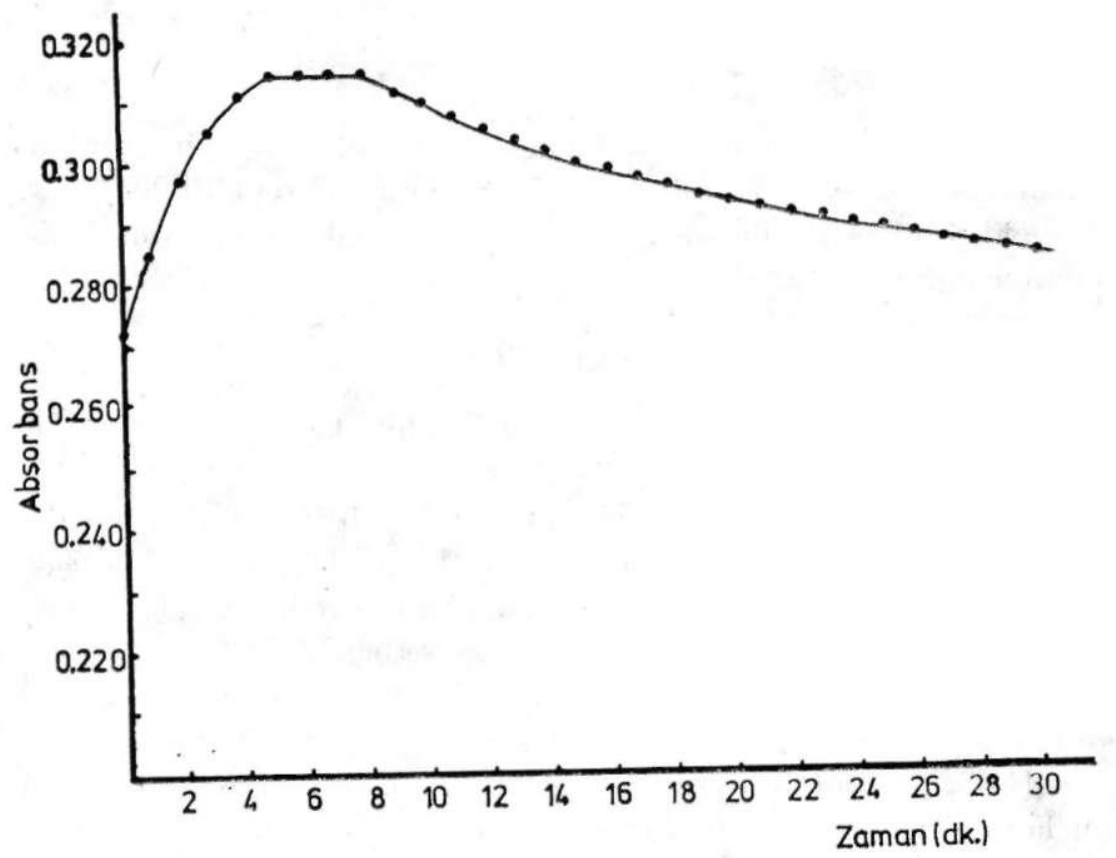

Şekil 2. Aminopirin $\mathrm{NH}_{4} \mathrm{SCN}$ tuzunun bcnzaldehit -benzilalkol (1:1) deki çözeltisinin ESR spektrumundaki pik yüksekliklerinin zamana karşı çizilen grafiği.

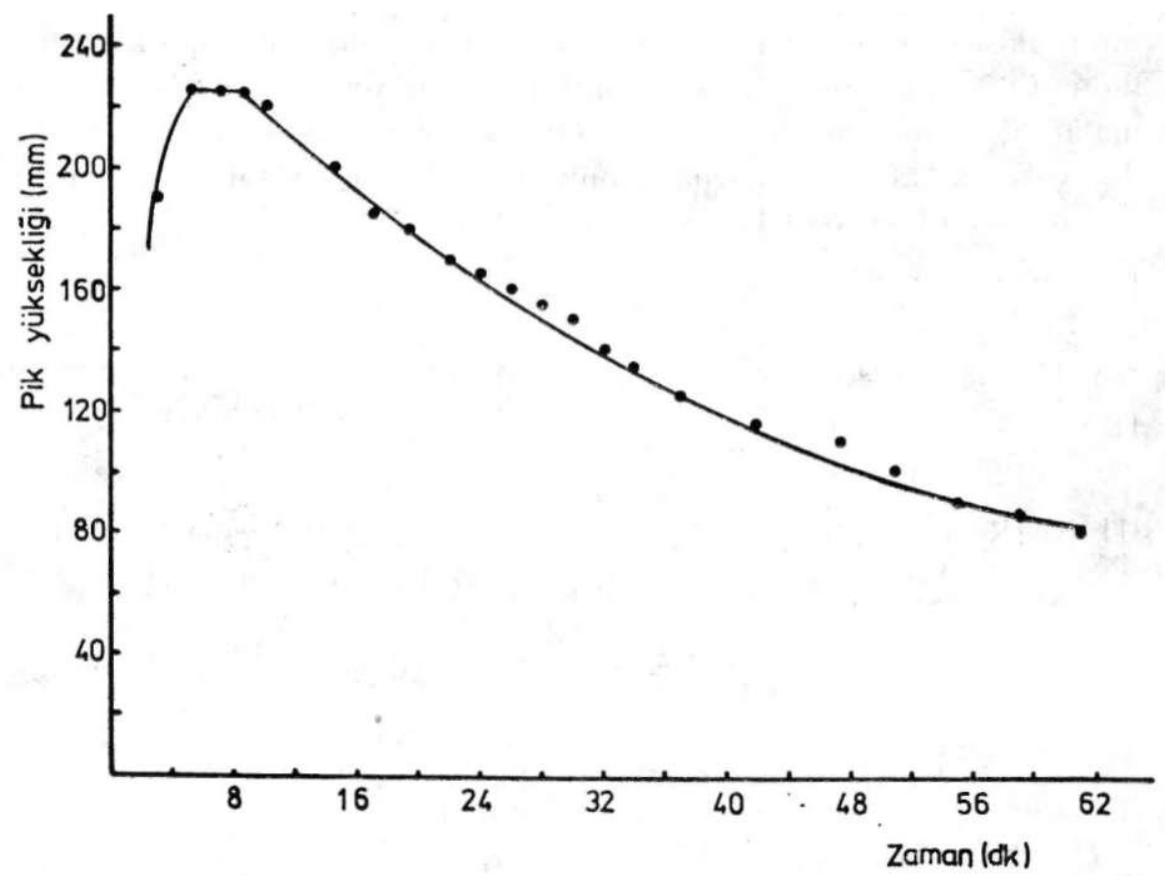

Şekil 3. Aminopirin $\mathrm{NH}_{4} \mathrm{SCN}$ tuzunun benzaldehit -benzilalkol (1:1) karışımı içindeki çözeltisinin $590 \mathrm{~nm}$ deki absorbsiyonunun zamana karşı çizilen grafiği. 
olmadığı ayrıca çözeltinin mavi renginin de sabit kaldığı görüldü. $\mathrm{Bu}$ sıcaklıkta çözücününde donması nedeniyle mavi renkli bileşik katı olarak elde edilemedi. Bu sonuç mavi rengin radikalik oluşuma bağlı olduğunu doğrulamaktadır.

\section{4) NMR ile yapilan analizler ( $\left.{ }^{1} \mathrm{H}-\mathrm{N} M \mathrm{R}\right)$}

Aminopirin $\mathrm{NH}_{4} \mathrm{SCN}$ tuzunun benzaldehitteki çözeltisinin N M R spektrumunda $\delta=2.6 \mathrm{da} \mathrm{C}-\mathrm{CH}_{3}, \delta=3.1 \mathrm{de} \mathrm{N}-\mathrm{CH}_{3}, \delta=3.2$ de $\mathrm{N}\left(\mathrm{CH}_{3}\right)_{2}$ protonlarına ait tekli pikler ve $\delta=8-9$ da $\mathrm{C}_{6} \mathrm{H}_{5}$ protonlarına ait pik grubu görülmektedir. Ve $\delta=3.2$ deki pikin şiddeti de zamanla düşmektedir. Aynı tuzun benzaldehit-benzilalkol (1:1) karışımmdaki çözeltisinin N M R spektrumunda ise benzilalkolün $-\mathrm{C} \mathrm{H}_{2}-$ ve $-\mathrm{OH}^{\prime} \mathrm{a}$ ait proton piklerine ilaveten $\delta=3.1 \mathrm{de} \mathrm{C}-\mathrm{CH}_{3}{ }^{\prime} \mathrm{e}$ ait tekli pik, $\delta=3.6$ da $\mathrm{N}-\mathrm{CH}_{3}{ }^{\prime}$ e ait tekli pik görülmekte buna karşılık $-\mathrm{N}\left(\mathrm{C}_{3}\right)_{2}$ protonlarına ait pik görülmemektedir. Elde edilen bu sonuçlara göre reaksiyonun $\mathrm{N}\left(\mathrm{C}_{3}\right)_{2}$ grubu üzerinden yürüdüğü anlaşılmaktadır. Buna ait pikin şiddetindeki zamanla azalma ESR ve UV-visible spektrumlarındakiler ile paralellik göstermektedir.

5) Reaksiyonumuzun renk değişim sırasındaki meydana gelen son renk sarıdır ve mavi renge göre daha uzun süre dayanıklı kalmaktadır. Oluşan bu bileşiğin yapısının aydınlatılması için yapılan çalışmalarda, ortama eter ilave edildiğinde bu sarı renkli bileşiğin ortamda dan çökerek katı halde ayrıldı̆̆ı bulundu. Elde edilen bileşiğin analizlerinde aşağıdaki sonuçlar elde edildi:

$\mathrm{En}: 279^{\circ} \mathrm{C}$

UV: $\lambda_{\max }^{\mathrm{M}_{\mathrm{e}} \mathrm{OH}}: 231$ ve $267 \mathrm{~nm}$ de

IR: $3330 \mathrm{~cm}^{-1}(\mathrm{OH}), 1660 \mathrm{~cm}^{-1}(\mathrm{C}=0), 1315 \mathrm{~cm}^{-1} \quad(\mathrm{C}-\mathrm{N})$, $\left.1126 \mathrm{~cm}^{-1}\right)(\mathrm{C}-\mathrm{O})$

${ }^{1} \mathrm{H}-\mathrm{NMR}: \delta=1.3\left(\right.$ triplet $\left.-\mathrm{CH}_{2}-\mathrm{CH}_{2}\right), \delta=2.2($ singlet $\mathrm{N}-\mathrm{CH}$,

$$
\delta=2.9 \text { (singlet }-\mathrm{OH}) \delta=7-8 \text { (multiplet } \mathrm{C}_{6} \mathrm{H}_{5} \text { ) }
$$

Kütle spektrumu: $\mathrm{M}+406$ (moleküler iyon \% 11.03)

$$
\begin{array}{lrlll}
\mathrm{m} / \mathrm{e} & 372 & (\mathrm{M}+-334 & \% 45.2) \\
\mathrm{m} / \mathrm{e} & 252 & (\mathrm{M}+-221 & \% 5.15) \\
\mathrm{m} / \mathrm{e} & 203 & (\mathrm{M}+-203 & \% & 6.21) \\
\mathrm{m} / \mathrm{e} & 111 & (\mathrm{M}+-295 & \% & 100) \\
\mathrm{m} / \mathrm{e} & 77 & (\mathrm{M}+-329 & \% & 78.48) \\
\mathrm{m} / \mathrm{e} & 30 & (\mathrm{M}+-376 & \% & 18.33)
\end{array}
$$


Elementer analiz:

C $\% 64.89, \mathrm{H} \% 5.36, \mathrm{~N} \% 13.70, \quad \mathrm{O} \% 15.68$

İnce tabaka kromatografisi:

$\mathrm{CHC}_{3} / \mathrm{Metanol} /$ Asetik asit $(7 / 3 / 0.5) \quad \mathrm{R}_{\mathrm{f}}: 0.65$

Elde edilen bu analiz sonuçlarının değerlendirilmesi ve materyal yöntem bölümünde hazırlanış biçimi belirtilen bis-( 1 -fenil-2-metil-4-hidroksi-5-okso-pirazolinil-3)-etan bileşiğinin aynı analizlerinin sonuçları ile karşılaştırılarak elde edilen sarı renkli bileşiğin bu bileşik olduğu saptandı (Formül 2)

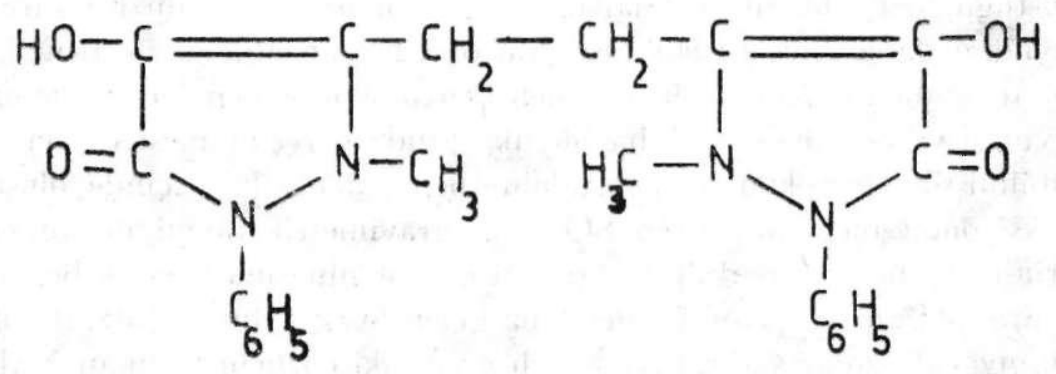

Formül 2

6) Aminopirin $\mathrm{NH}_{4} \mathrm{SCN}$ tuzunun benzaldehitteki çözeltisinde meydana gelen renk değişiminin sonunda çözeltinin renksiz olduğu ve geride beyaz bir kalıntının oluştuğu görülmektedir. Bunun üzerinde yapılan analizlerde bileşiğin $\left(\mathrm{NH}_{4}\right)_{2} \mathrm{SO}_{4}$ olduğu belirlendi. Benzaldehit-benzilalkol içerisindeki reaksiyonun bitiminde gravimetrik olarak yapilan $\mathrm{SO}_{4}{ }^{-2}$ tayinleri sonucunda aminopirin $\mathrm{NH}_{4} \mathrm{SCN}$ deki bir mol $\mathrm{NH}_{4} \mathrm{SCN}^{\prime}$ ün $1 \mathrm{~mol}\left(\mathrm{NH}_{4}\right)_{2} \mathrm{SO}_{4}{ }^{\prime}$ a dönüştüğünden hareketle yapılan hesaplamalarda, başlangıçtaki aminopirinin \% 60'ının bu reaksiyona girdiği bulundu. Bu oran AWE, BUERHOP, BAMMEL (9) e göre $\mathrm{AgNO}_{3}$ ile olan reaksiyonda \% 50 olarak gerçekleşmektedir. Benzaldehitteki reaksiyon sonucunda oluşan $\mathrm{SO}_{4}{ }^{-2}$ miktarı ise çok düşük olduğu için duyarlı olarak hesaplanamadı.

\section{SONUÇ ve TARTIŞMA}

Anlatılan şartlarda ilk kez tarafımızdan gözlenen ve renk değişimi ile yürüyen reaksiyonumuzun, benzaldehit gibi reaktivitesi yüksek ve fiziksel özellikleri nedeniyle içinde çalışılması oldukça zor olan bir 
çözücüde gerçekleşmiş olması mekanizmasının belkide bazı basamaklarının tam açıklanmasına imkan vermemesine karşılık UV, IR, NMR, ESR ve diğer analizler ile incelenmesi sonucunda mavi renkli radikal oluşumu ile başlayan bir oksidasyon reaksiyonu olduğu kanısına varıldı. Oksidasyon olayı düşüncemize göre şöyle gerçekleşmektedir; bilindiği gibi benzaldehit kolaylıkla indirgenebilen bir maddedir. Sulfosiyanür, benzaldehit ile karşılaşınca sulfata yükseltgenmekte, benzaldehit ise benzilalkole indirgenmektedir. Bu indirgenmeye karşılık aminopirin oksidasyona uğramaktadır. Bunun ilk basamağıda mavi renkli radikal oluşumudur $(5,8,9)$.

Reaksiyon yalnızca benzaldehit içinde yürütüldüğünde çok hızlı oluştuğu, benzaldehit-benzilalkol karışımı içinde ise uzun bir süreye yayıldığı daha önce belirtilmişti. Bu olayda benzaldehit ile benzilalkol arasındaki dengenin ilave edilen benzilalkol ile benzaldehit lehine kayması ve reaksiyonun daha büyük oranda gerçekleşmesi ile açıklanabilmiştir. Gerçektende benzaldehit-benzilalkol (1:1) içinde oluşan reaksiyonda meydana gelen $\mathrm{SO}_{4}{ }^{-2} 1 \mathrm{n}$ gravimetrik tayini ile aminopirin'in \% 60 ının reaksiyona girdiği hesaplanmasına karşılık benzaldehitte oluşan reaksiyonda meydana gelen $\mathrm{SO}_{4}^{-2}$ duyarlı olarak saptanmıyacak kadar azdır. Ayrıca adı geçen iki çözücüde alınan NMR spektrumları karşılaştırıldığında da benzer sonuca varılmaktadır, benzaldehitte $-\mathrm{N}\left(\mathrm{C}_{3}\right)_{2}$ protonlarına ait pik spektrumda şiddeti düdüşen biçiminde gözlenirken benzaldehit-benzilalkol (1: 1) karışımında bu piklerin kaybolduğu görülmektedir.

1- Onur, F., Aminopirinin Yeni bir Renk Reaksiyonu, J. Fac. Pharm. Ankara 13, 54 (1983)

2- Kaufmann, H.P., Verfahren zur Darstellung von Wasserlöslichen Verbindungen des 1-phenyl-2, 3-dimethyl-4-dimethyl amino-5-pyrazolons mit Anorganischen Rhodaniden. Reichspatentamt Patentschrift, Deutschland, 27 Mai 1933

3- Pinxteren, J.A.C., Verloop, M.E., De Vorming van Nevenprodukten Bij de Oxidimetrische Bepaling van Enige Prazolonen (II), Pharm. Weekblad 110, 61 (1975)

4- Pechtold, F., Untersuchungen über den Oxydativen Abbau von Derivaten des 4-aminophenazonc, Arzneimittel-Forschung 14(4), $258 \quad$ (1964)

5- Awe, W., Stoy, E., Buerhop, R., Die Einwirkung von Oxydation mittein auf 4-dimethylamino-1-phenyl--2,3-dimethyl-pyrazol-5-on (Pyramidon), Arch. Pharm. 293, 489 (1960) 
6- Tomankova. H., Zyka. J., The Oxydation of Aminophr-nazone by Hydrogen Peroxide, Microchem. J. 20, 132 (1975)

7- Awe, W., Buerhop, R., Die Einwirkung von Oxydationmilteln auf 4-dimethylamino1-phenyl-2, 3-dimethyl-pyrazol-5-on (Pyramidon), Arch. Pharm. 292(64), 749 (1959)

8- Awe, W., Stoy-Geilich, E., Buerhop, R., Bammel, H., Die Einwirkung von Oxydationmitteln auf 4-dimethylamino-1-phenyl-2,3-dimediyl-pyrazol--5-on, Arzneimittel-Forschung 10, 796 (1960)

9- Awe, W., Buerhop, R., Bammel, H., Studien zu der Bekannten Reaktion des Pyramidons mit Silbernitrat, Pharm. Ztg. 106, 1611 (1961)

10-Reisch, J., Über die Photochemie Arzneilich Verwendeter Pirazolin Derivative, Gyogyszereszel 19, 81 (1975) 